\title{
Jean-Martin Charcot: The Father of Neurology
}

\author{
David R. Kumar; Florence Aslinia, MD; Steven H. Yale, MD; \\ and Joseph J. Mazza, MD
}

Keywords:

Amyotrophic lateral sclerosis

Charcot's joint

Multiple sclerosis

Charcot

\section{Reprint Requests:}

Steven H. Yale, MD

Department of Clinical Research

Marshfield Clinic Research Foundation

1000 North Oak Avenue

Marshfield, WI 54449

Tel.: 7| $5-387-9 \mid 10$

Fax: 7I5-389-5757

E-mail: yale.steven@marshfieldclinic.org

Received: August 27, 2009

Revised: November 10, 2009

Accepted: December 16, 2009

doi: $10.3|2| / \mathrm{cmr} .2009 .883$
To take away from neurology all the discoveries made by Charcot would be to render it unrecognizable.

Joseph Babinski ${ }^{1}$

ean-Martin Charcot (figure 1) was born in Paris, France in 1825 at a time when the field of Neurology had not been formally recognized as a distinct specialty. ${ }^{2}$ He was a gifted painter who used his artistic abilities and strong visual memory to make associations about patterns of disease in the field of medicine and anatomy. ${ }^{1}$ His father, financially limited, decided that the son who performed best amongst the four in school would go on to receive a higher education, a competition that Jean-Martin won, thus providing him the opportunity to enter medical school. ${ }^{3}$ Mastery of the French, English, German, and Italian languages enabled him to read the medical literature in these languages, which accounted for his well-rounded knowledge of a variety of subjects including gerontology, diseases of the joints and lungs, and the anatomy, physiology, and pathology of the nervous system. ${ }^{4}$

\section{Academic Career}

After finishing medical school at the age of 23, Charcot worked as an intern at the "Hospital de la Salpêtrière." $A$ well received thesis on the differentiation of gout from chronic rheumatoid arthritis propelled him to "Chef de Clinique" in 1853, a position he would hold for three years before being appointed "physician to the hospitals of Paris" in 1856. ${ }^{5,6}$ Despite the Franco-Prussian War (1870-1871) and the revolt of Paris temporarily halting his professional assent, the appointment as "Professor of the Pathological Anatomy at the University of Paris" in 1872 would be a pivotal turning point in his career. ${ }^{4}$

Charcot, who was trained as a pathologist, recognized the important relationships between clinical and anatomical findings. ${ }^{1}$ He gathered extensive data through clinical observations, including changes in a patient's clinical status (clinical signs and symptoms), and subsequently correlated them with findings on autopsy (pathology). ${ }^{1}$ Although Laennec (the inventor of the first stethoscope) played a prominent role in revising this method (anatomoclinical method), which was initially taught by Italian pathologist Giovanni Morgagni (1682-1771), Charcot brought this idea back to the forefront by demonstrating the technique daily to his fellow clinicians, students, and the public. ${ }^{1,7}$ 


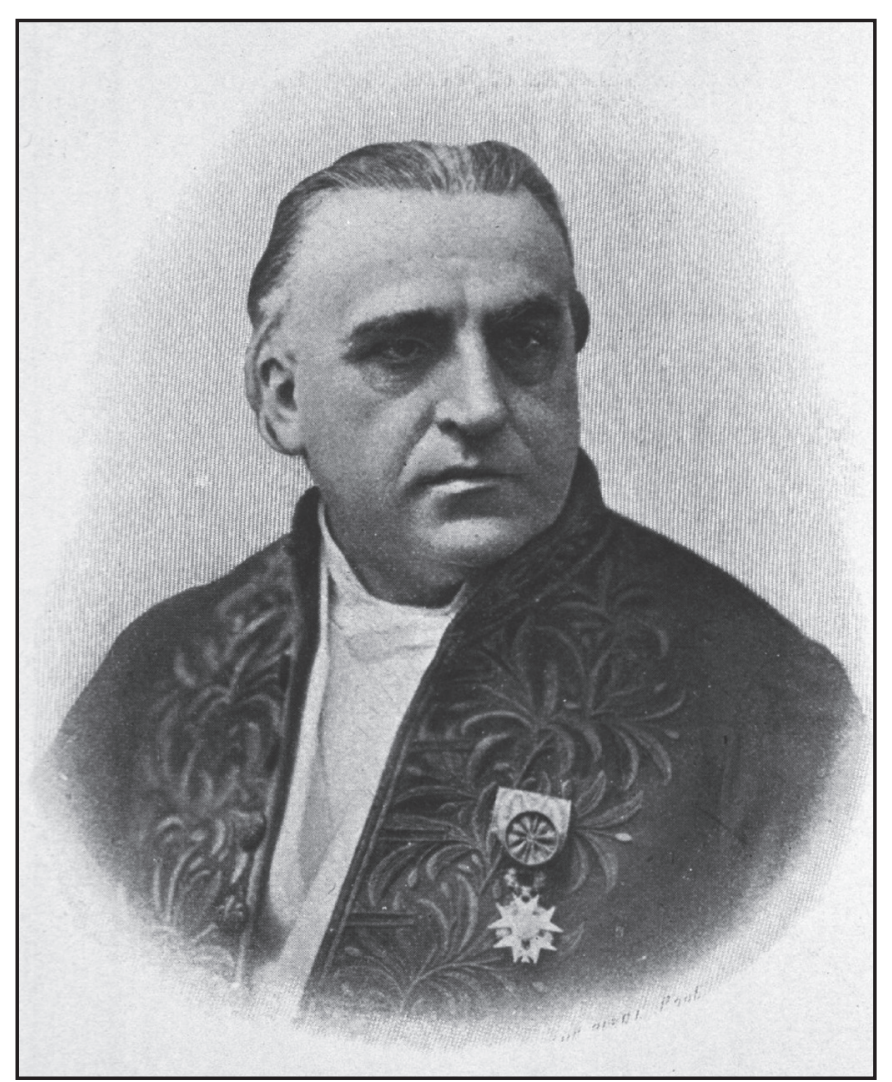

Figure 1. Jean-Martin Charcot (1825-1893). Courtesy of the US National Library of Medicine.

As professor of pathological anatomy, he lectured on diseases of all organs while providing cadavers and specimens for students. Some of his students that would go on to become well-known physicians include Sigmund Freud, Charles Babinski, and Gilles de la Tourette. ${ }^{4,8}$ Charcot had a special method of teaching that distinguished him from other professors, utilizing a unique and innovative teaching style for the time period, which included interviewing one or more patients diagnosed with the same condition during case presentation, imitating neurological symptoms of the patients, and drawing pictures illustrating the main clinical findings of a disease. ${ }^{5,8}$ Furthermore, as photography became popular, this new tool enabled him to capture the main features of particular diseases and to demonstrate them to his audience. ${ }^{7}$

\section{The Salpêtrière Hospital}

Originally constructed by Louis XIII as a gun factory and place to store gunpowder during the $16^{\text {th }}$ century, Charcot would develop the Salpêtrière into a premier center for neurology. ${ }^{1}$ He was instrumental in converting this building in the $17^{\text {th }}$ century to the Salpêtrière Hospital from monies received from charitable organizations, including the Vincent de Paul foundation. ${ }^{2}$ A state-of-the-art neurological center for its time, Charcot established a pathology lab and introduced opthalmoscopy, photography, and microscopy at the Salpêtrière. ${ }^{6}$ Used as an asylum for beggars, prostitutes, and the insane, he referred to this hospital as a place of "grand asylum of human misery." ${ }^{8}$ Charcot was officially responsible for the oversight of medical care at Salpêtrière, having a patient population around 5000 in 1862 , with nearly 3000 suffering from neurological diseases, providing him with a vast number of cases in which he could conduct his studies. ${ }^{6}$ In an attempt to bring about order and make it easier for future physicians to conduct studies on these subjects, Charcot and one of his colleagues examined each of the patients and classified them according to their specific neurological disorder. ${ }^{2}$ His trip to London for the International Medical Congress in 1881 brought international recognition to Charcot and the Salpêtrière for their progress in neurology, and created suitable circumstances for the French Parliament to create and appoint Charcot as Chair in diseases of the nervous system. ${ }^{3,5}$

\section{Founder of Modern Neurology}

In addition to providing a complete clinical description coupled with the pathological changes associated with a variety of neurological diseases, allowing for their precise classification, Charcot's other significant accomplishments include the following: describing the brain's vascular supply, differentiating tremors found in Parkinson's disease with those of patients with multiple sclerosis, differentiating hysteria from epilepsy, being one of the first physicians to set up rehabilitation clinics for the treatment of his patients, and formulating a triad (known as the Biliary Triad) for diagnosing acute cholangitis which consists of right upper quadrant pain, jaundice and fever. ${ }^{9}$

\section{Multiple Sclerosis}

The first description of multiple sclerosis (MS) dates back to the $14^{\text {th }}$ century, but it was Charcot and the use of the anatomoclinical method that made the first correlations between the clinical features of MS and the pathological changes noted post-mortem. ${ }^{3,10}$ The recognition of MS as a distinct disease was quite a feat for the time, as many diseases in the early $19^{\text {th }}$ century that would now be categorized as either neurological or psychiatric would have been grouped into a general class of "nervous disorders," with no separation between individual conditions. ${ }^{11}$ Such an attempt at the classification of neurological diseases had not been undertaken prior to Charcot. ${ }^{2,6}$ Only a small group of illnesses such as epilepsy, paraplegia, and neurosyphilis were differentiated at the time. ${ }^{11}$

Although Sir Robert Carswell noted the presence of demyelinating lesions associated with MS, and Jean Cruveilhier was the first to document the clinical findings from a patient that would later develop demyelinating lesions, the implications of these findings were not fully understood. ${ }^{12}$ Charcot's detailed description of MS in 1868 (described as "la sclérose en plaques"), accompanied by the first drawings illustrating the expansions of lesions from the ventricles into the cerebral hemispheres, provided the earliest insight into the pathology of MS involving both the brain and spinal cord..$^{12,13}$ He would go on to fully describe the various forms of MS 
(cephalic, spinal, and mixed/cerebrospinal), once again correlating the symptoms at presentation with findings post-mortem. ${ }^{12}$

In addition to lecturing about this disease on a regular basis, Charcot was the first person to diagnose MS on a living patient. ${ }^{9,12}$ In fact, he even formulated a triad for diagnosing MS (nystagmus, intention tremor, and scanning speech). ${ }^{9}$ Though lacking in specificity, it remains important as it was an attempt to separate this disease from similar diseases affecting the nervous system. ${ }^{14}$ Remarkably, the relevance of some of his histopathological observations have only recently been acknowledged, such as axonal transaction within plaques and remyelination. ${ }^{11}$

\section{Amyotrophic Lateral Sclerosis}

Similar to Charcot's other discoveries, it was through careful clinical observation and meticulous work in the laboratory detailing the pathophysiology that allowed for establishment of amyotrophic lateral sclerosis (ALS) as a separate disease. ${ }^{6}$ He described and diagnosed the first cases of ALS as a specific neurological disease associated with a distinct pathology. ${ }^{15}$ Studies conducted between 1865 to 1869 by Charcot and his colleague Joffroy found that lesions within the lateral column in the spinal cord resulted in chronic progressive paralysis and contractures (no atrophy of muscles), while lesions of the anterior horn of the spinal cord resulted in paralysis without contractures (with atrophy of muscles). ${ }^{15}$ These findings supported his hypothesis at the time that the motor component of the spinal cord consisted of a two-part system, and that the location of the lesion results in a varying clinical presentation. ${ }^{15}$ While the term "amyotrophic lateral sclerosis" was not offered by Charcot until 1874 when his lectures were compiled into a collection of his work titled "Oeuvres Completes," ALS is still referred to as Charcot's disease in many parts of the world. ${ }^{1,15}$ While numerous molecular and genetic discoveries have allowed for a greater understanding of this disease, his original descriptions of the associated clinical and pathological findings of ALS have remained virtually unaltered. ${ }^{15}$

\section{Charcot's Joint}

The first to describe arthropathies in patients with tabes dorsalis, Charcot noted that these patients experience sharp, quick pains prior to the ensuing joint destruction and eventual development of ataxia. ${ }^{8}$ In tabetic patients, he hypothesized that "...the arthropathy of ataxic patients seems to always start after the sclerotic changes have taken place in the spinal cord." ${ }^{16}$ Giving credit to others before him in his first description of tabetic arthropathies in 1868, Charcot made reference to J.K. Mitchell, who in 1831 was the first to suggest an association between spinal lesions and arthropathies in the foot and ankle of patients with rheumatologic diseases. $^{16,17}$

The loss of sensation and pain perception that occurs in patients with arthropathies results in continued weight bearing and stress of the weakened joints, leading to bone fractures and further destruction of the joint and soft tissue. ${ }^{18,19}$ After a period of acute inflammation, structural weakening occurs followed by eventual healing or consolidation, at which point the bone is deformed. ${ }^{20}$ However, the involvement of the small bones and joints of the foot in tabetic arthropathies was not described until 1881 at the $7^{\text {th }}$ International Medical Congress by English physician Herbert W. Page (though not fully recognized until 1883 when presented to the Clinical Society of London.) Prior to this, most observations involved the longer bones and their larger articulations. ${ }^{21}$ Also in 1883, Charcot and his colleague Fere described involvement of the foot in patients with tabes dorsalis, coining the term "pied tabetique" which has come to be known as Charcot's foot. ${ }^{18}$

While syphilis was the most common cause of Charcot's joint in the mid to late $19^{\text {th }}$ century, William Jordan recognized the association between diabetes mellitus and neuropathic arthropathies in 1936. ${ }^{16,20}$ Currently, Charcot's joint is believed to be present in up to $35 \%$ of patients with diabetic neuropathy, but this number may be an underestimate, since Charcot's joint is difficult to diagnose. ${ }^{19}$

\section{Charcot-Marie-Tooth Disease}

The degeneration of the peripheral nerves, nerve roots, and even the spinal cord leading to progressive weakness and wasting of the distal muscles of the legs and arms was initially described by Schultze in $1884 .{ }^{9}$ However, it was the work of Charcot that brought further elucidation of the disease by first correctly labeling it as a neuropathy rather than a myopathy. ${ }^{9}$ This peroneal form of muscular atrophy, which was described by Howard Tooth in the same year as Charcot and his assistant Pierre Marie, has now come to be known as Charcot-MarieTooth Disease (CMT). ${ }^{7}$

Currently there are at least 25 genes associated with CMT, which is the most commonly inherited neuromuscular disorder. ${ }^{22}$ A slowly progressive disease, usually with an early onset, many of the mutations that are known to cause CMT occur in genes that encode for proteins in a variety of locations, such as the myelin, Schwann cells and axons. ${ }^{23}$ CMT is generally divided into one of two forms based on nerve-conduction studies, those being either demyelinating (CMT 1) or axonal (CMT 2), as clinical features do not allow for differentiation between the two. ${ }^{22,23}$ Regardless of the form of CMT, this peripheral neuropathy eventually manifests itself through axonal degeneration of, most commonly, the longest and largest sensory and motor nerve fibers. ${ }^{23}$

In Charcot and Marie's original publication titled "Concerning a Special Form of Progressive Muscular Atrophy," they mentioned that similar cases had been published in the literature. ${ }^{24}$ However, Charcot notes that none of the previous descriptions were done objectively or thoroughly, and that most descriptions of the disease only briefly noted that it was hereditary. ${ }^{24}$ Therefore, he felt it was necessary to provide a complete description of the disease in order for more attention 
to be devoted to it. ${ }^{24}$ At a time when technology was limited, we must not forget how astute Charcot was to argue that CMT was a neuropathy and not a myopathy based solely on clinical observations.

\section{Conclusion}

Charcot's contributions to medicine and the medical literature are legendary. His lectures have been published in a variety of languages and still remain an essential part of any neurologist's library. ${ }^{15}$ His astuteness as a clinician and the ability to connect the clinical observations to the pathology of a disease have cemented his legacy as one of the most influential physicians of all time. While the correlation between clinical observations and pathological findings post-mortem seems trivial in our day and age, Charcot applied this method to bring order to the vast number of neurological diseases that lacked a proper description and classification. We must also appreciate the ability of Charcot to draw accurate and precise conclusions without the aid of modern technology.

More importantly, the heightened awareness that Charcot brought to so many diseases such as MS, ALS, CMT, and other neurological conditions has led to further research into these conditions with hopes for better therapeutic treatments. ${ }^{3}$ Establishing the basis for Neurology as a separate specialty, it will forever be indebted to Charcot for his contributions and profound insight which have helped shape and will continue to shape the field for years to come.

\section{References}

1. Tan SY, Shigaki D. Jean-Martin Charcot (1825-1893): pathologist who shaped modern neurology. Singapore Med J 2007:48:383-384.

2. Tollis D. Who was Charcot? Nursing Times 1996;92:56-57.

3. Clanet M. Jean-Martin Charcot. 1825 to 1893 . Int MS J 2008;15:59-61.

4. Dubb A. Jean-Martin Charcot (1825-1893): His life and his legacy. Adler Mus Bull 1993;19:19-24.

5. Thorburn AL. Jean Martin Charcot, 1825-1893. An appreciation. Br J Vener Dis 1967;43:77-80.

6. Jay V. The legacy of Jean-Martin Charcot. Arch Pathol Lab Med 2000;124:10-11.

7. Charcotian eponyms. South Med J 1975;68:1592.

8. Sanders LJ. Jean-Martin Charcot (1825-1893). The man behind the joint disease. J Am Podiatr Med Assoc 2002;92:375-380.

9. Kundu AK. Charcot in medical eponyms. J Assoc Physicians India 2004;52:716-718.

10. Lublin F. History of modern multiple sclerosis therapy. J Neurol 2005;252 Suppl 3:iii3-iii9.

11. Murray TJ. The history of multiple sclerosis: the changing frame of the disease over the centuries. J Neurol Sci 2009;277 Suppl 1:S3-8.

12. Pearce JMS. Historical descriptions of multiple sclerosis. Eur Neurol 2005;54:49-53.

13. Orrell RW. Multiple Sclerosis: The history of a disease. [Book Review]. J R Soc Med 2005;98:289.

14. Poser CM, Brinar VV. Diagnostic criteria for multiple sclerosis. Clin Neurol Neurosurg 2001;103:1-11.

15. Goetz CG. Amyotrophic Lateral Sclerosis: Early Contributions of Jean-Martin Charcot. Muscle Nerve 2000;23:336-343.

16. Sanders LJ. The Charcot foot: historical perspective 1827-2003. Diabetes Metab Res Rev 2004;20 Suppl 1:S4-S8.
17. Thompson P, Hanson D, Langemo DK, Hunter S, Anderson J. Diabetic foot: Charcot neuropathic osteoarthropathy. Adv Skin Wound Care 2009;22:72-73.

18. Frykberg RG, Belczyk R. Epidemiology of the Charcot foot. Clin Podiatr Med Surg 2008;25:17-28.

19. Shah MK, Hugghins SY. Charcot's joint: an overlooked diagnosis. J La State Med Soc 2002;154:246-250.

20. Pinzur MS. Charcot's foot. Foot Ankle Clin 2000;5:897-912.

21. Sanders LJ. What lessons can history teach us about the Charcot foot? Clin Podiatr Med Surg 2008;25:1-15.

22. Szigeti K, Lupski JR. Charcot-Marie-Tooth disease. Eur J Hum Genet 2009;17:703-710.

23. Pareyson D, Marchesi C. Diagnosis, natural history, and management of Charcot-Marie-Tooth disease. Lancet Neurol 2009;8:654-667.

24. Brody LA, Wilkins RH. Charcot-Marie-Tooth disease. Arch Neurol 1967;17:552-557.

\section{Author Affiliations}

David R. Kumar, BS ${ }^{*}$; Florence Aslinia, MD广s;

Steven H. Yale, MD*广; Joseph J. Mazza, MD*

*Department of Clinical Research, Marshfield Clinic

Research Foundation, Marshfield, Wisconsin, USA

tDepartment of Internal Medicine, Marshfield Clinic, Marshfield, Wisconsin, USA

Current Affiliation: University of Wisconsin, School of

Medicine and Public Health, Madison, Wisconsin, USA

$\S$ Current Affiliation: Division of Gastroenterology and

Hepatology, University of Maryland School of Medicine,

Baltimore, Maryland, USA 